\title{
Demand chain management — The evolution
}

\author{
D Ericsson* \\ Received: 12 April 2011; Revised: 7 June 2011; Accepted: 12 June 2011
}

\begin{abstract}
The concepts of Supply Chain Management (SCM) and Demand Chain Management (DCM) are among the new and debated topics concerning logistics in the literature. The question considered in this paper is: "Are these concepts needed or will they just add to the confusion?" Lasting business concepts have always evolved in close interaction between business and academia. Different approaches start out in business and they are then, more or less simultaneously, aligned, integrated, systemised and structured in academia. In this way a terminology (or language) is provided that helps in further diffusion of the concepts.

There is a lack of consensus on the definition of the concept of SCM. This may be one of the major reasons for the difficulty in advancing the science and measuring the results of implementation in business. Relationships in SCM span from rather loose coalitions to highly structured virtual network integrations. DCM is a highly organised chain in which the key is mutual interdependence and partnership. The purpose is to create a distinctive competence for the chain as a whole that helps to identify and satisfy customer needs and wishes.

The classical research concerning vertical marketing systems is very helpful in systemising the rather unstructured discussions in current SCM research. The trend lies in increasing competition between channels rather than between companies, which in turn leads to the creation of channels with a high degree of partnership and mutual interdependence between members. These types of channels are known as organised vertical marketing systems in the classic marketing channel research. The behaviour in these types of channels, as well as the formal and informal structures, roles in the network, power and dependence relations, etc. are well covered topics in the literature. The concept of vertical marketing systems lies behind the definition of demand chains and demand chain management proposed in this paper. A demand chain may be defined as an integrated and aligned chain built on partnership and mutual interdependence aiming at the creation of a unique competence to identify and satisfy customer perceived value, while demand chain management may be defined as the effort to create, retain and continuously develop a dynamically aligned demand chain.
\end{abstract}

Key words: Marketing channels, vertical marketing systems, logistics, supply chain management, demand chain management.

\section{Introduction}

Logistics is a fascinating discipline undergoing continuous evolution based on interaction between changes in the environment and the development of new tools and techniques. Logistics development started with military logistics. Napoleon was the first to use the

${ }^{*}$ School of Engineering, University of Boras, Sweden, email: dag.ericsson@telia.com 
term when he appointed a marechal de logistique. Logistics became an integral part of the tripod consisting of strategy, tactics and logistics. Logistics was the operational means of supplying armies with what was needed to achieve their strategic and operational goals (Von Clausewitz 1968 and Van Crefeld 1977). Even before Napoleon efficient logistics was a necessity in war. Alexander the Great, Hannibal, and the Swedish king, Gustaf II Adolf, are all well-known masters in the art of war based on logistics. Other warriors were less successful, and, as many examples show, when logistics failed, the entire mission failed. The invasion of Normandie in 1945 was a major exercise in effective and efficient logistics. When high ranking officers returned home, the first non-military applications of logistics emerged.

\section{Market development and the evolution of management concepts}

Concepts, strategies and business models evolve in the interplay between business and the environment (Ericsson 1996, 2007). The environment is changing rapidly at the moment, which requires new concepts and business models. This evolution has been going on for some time, and new patterns of behaviour are now emerging. If simplified, it may be concluded that we are moving away from a milieu characterised by the old industrial paradigm, and towards a milieu characterised by the knowledge society. From a logistics point of view, this implies that we are shifting focus from working in a relatively stable environment to a volatile and rapidly changing environment. We are moving from supplier driven mass production and mass marketing towards a consumer driven mass customisation based on consumer insight and relationship marketing. The old model was based on low cost production of standardised products with focus on operational efficiency, but the new model is based on strategic positioning and innovative products with a very high perceived consumer value.

In the old model the companies were also working relatively autonomously and independent of each other in the distribution channel. The lack of coordination and integration was compensated by increasing inventories, and the channel consisted of "loose coalitions" of companies. The new model is based on intense information exchange, collaboration and virtual networks. In these networks, links are developed consisting of companies who have decided to work in close partnership to create added perceived customer value. This unique competence is created by the interaction and interdependence in the chain as a whole, and cannot be attributed to any specific company. The distinctive competitive competence is based on the entire channel - the demand chain.

Success with such an approach is built on trust among the partners in the network and the creation of win-win situations. The mental move from mutual competition to mutual cooperation is a major tumbling stone for the development. However, competition increases and forces the creation of new visions, new business models and new mind sets. The tools for integration and collaboration are available (e.g. within Information and Communication Technology (ICT)), and the challenge is to create acceptance for new mindsets and new ways of behaviour. Most of the approaches still used in business are based on the old business paradigm with focus on intra company effectiveness and efficiency. In the new 
business paradigm there is more focus on interorganisational relationships. Supply Chain Management (SCM) is one of the newer concepts dealing with this evolving complexity. However, there is only some agreement on what SCM really is, and how it should be implemented. Stock (2009, p. 148) concludes after a thorough review and analysis of research literature concerning SCM that "while SCM has been around for 25+ years, there is still no consensus definition of the field and what it entails... For SCM theory development, constructs must be defined specifically... Researchers will have to arrive at a consensus definition of SCM so that the discipline may move forward with the development of SCM theories and sub-theories."

Part of the problem is the fact that SCM relationships span from very loose, transactionoriented connections to rather long term, stable relations. This broad span might be one of the main reasons for the lack of common definition and the difficulty in measuring the results of the application of the concept.

The trend is that competition increasingly moves from company versus company to channel versus channel (Christopher 1992). This increases the necessity of shifting from considering individual companies and their actions in the channel to focusing on channel performance in a holistic way. It is very difficult for a company to act on its own in an increasingly global and competitive world. Hence there is a development toward a holistic view of the chain and the development of partnership.

There is a constant interplay between changes in the environment and the concepts, tools and techniques used in business. The market in most industries is changing from a rather stable to a highly unstable environment characterised by short product life cycles, high volatility, low predictability and a high degree of impulse buying by the consumer. The Demand Chain Management (DCM) concept is designed to fit this new environment by explicitly focusing on the customer and aligning interorganisational processes accordingly. The purpose is to create a unique competence aimed at identifying and satisfying customer needs and wishes. The term DCM is used in a number of different ways. It may be seen as an enlargement of SCM, or as a replacement, or as a synonym. The question is: "Is there really a need for a new term?"

When the SCM concept was introduced in the early 1980s, there was a similar discussion regarding the difference between Logistics Management (LM) and SCM (Cooper et al. 1997, Croxton et al. 2001, Stock 2000). It may be concluded that the SCM concept highlights the importance of process orientation to an even higher degree than LM, and focuses on the coordination and integration of the whole chain, i.e. from raw materials supplier to the ultimate user. The SCM approach was initially focused on the down stream flows in the chain. This push approach is now replaced by a pull orientation based on activities initiated by the end user, as highlighted by the following definition (Lambert 1994): "Supply chain management is the integration of business processes from end user through original suppliers that provides products, services and information that add value for customers."

It is clear that we do not need more academic concepts that are "forced" on practitioners. However, development in the business world often initiates the need for new terms and concepts. Industry leads the development and researchers attempt to structure, systemise and create frames of reference that may be used as a common language in business. 
Fredrick Taylor's concept Scientific Management was in many ways a summary and synthesis of different approaches and methods that were evolving in industry. Taylor's framework provided a frame of reference and a "language" that facilitated the diffusion and acceptance of the concept. Similarly, the Swedish concept of Materials Administration (MA) was a synthesis of approaches, methods and techniques that were evolving in industry under the boom of the 1960s. Swedish exports were increasing rapidly, and due to the long distance to the main markets in Europe there was a need for a more holistic approach to manage transportation, warehousing, materials handling and related physical flows. Swedish multinationals like Volvo, SKF, Atlas Copco, Sandvik and Astra were excellent seed beds and test centres for the MA concept that evolved in symbiosis between industry and academia.

MA/Logistics was defined as "The planning, development, coordination, organisation, control and review of the materials flow from raw materials supplier to the ultimate user" (Ericsson 1969, 1974). Since the beginning the Swedish concept of logistics was therefore focusing on the entire flow, and the approach was based on interorganisational relations much in the same way as the more recent SCM.

In 1982 the term SCM was coined by consultants who identified the evolving trends and applications in industry. The concept was later discussed, analysed and systemised at universities. The MA/Logistics concept was the cradle for process orientation and for the discussion of marketing channels and Vertical Marketing Systems (VMSs) as structured and highly organised systems (Ericsson 1976, 1996). Currently new approaches and business models are evolving in industry, and these are now summarised and synthesised in the DCM approach.

\section{The Swedish MA/Logistics concept - A discipline is born}

At the end of the 1960s a fundamental rethinking was initiated in Swedish industry. Sales were booming and new market opportunities were developing. There was a need for a new business model with a holistic view of the increasingly more important physical flow of products and components from production to consumption or use. This was a very exciting journey that resulted both in a new academic discipline, namely MA/Logistics, and the new profession of logistician. This development is well described in the licentiate thesis of Green (1989).

Logistics is the backbone and the origin of supply chain thinking. The evolution of logistics, therefore, provides an important background to what is happening today. Efficiency in operations and effectiveness in fulfilling customer needs are key words in designing total materials flows. In the late 1960s the vision was to create "An even, steady, uninterrupted, and quality assured flow from raw materials supplier to the ultimate user" (Ericsson 1969). This vision was realised by developments within ICT, development of new methods and techniques, but most of all, by well planned and organised academic education in logistics. The broader and more process oriented approach of MA/Logistics evolved, and was defined as "planning, development, coordination, integration, control and review of the total materials flow from raw materials supplier to the ultimate user" (Ericsson 1969). In the USA, several different concepts were also developing during the 1960 s to refer to ma- 
terials flow. For example, the notion of Materials Management focused on the inflow from suppliers (Ammer 1968), Business Logistics focused on transportation and internal flows (Ruppenthal et al. 1968) and Physical Distribution Management focused on the outflow to customers (Bowersox et al. 1970).

The logistics concept was a narrower approach, and for this reason MA was the initial term. When the international logistics concept broadened in the 1970s, these notions became synonymous. There is a strong resemblance between this definition and the more recent definitions of SCM (Christopher 1998 and Gattorna et al. 1998). Initially the focus of the MA approach was on creating efficiency within the company itself by tearing down walls and integrating activities in the materials flow. It started out with the coordination of operational activities such as transportation, materials handling and warehousing, and moved on to coordination on a more strategic level between basic materials flow functions such as purchasing, manufacturing and physical distribution. An explicit distinction was made between the approaches on the operational level, namely between so-called materials control, which is focused on improving efficiency within existing and given resources, and MA, which is focused on effectiveness by integrating and developing resources. This distinction was very helpful during the implementation phase since the change process is different when applied to given, operational activities in comparison with developing, strategic activities. At a somewhat later stage interfaces with product development and $\mathrm{R} \& \mathrm{D} /$ engineering and marketing were explicitly added, as shown in Figure 1.

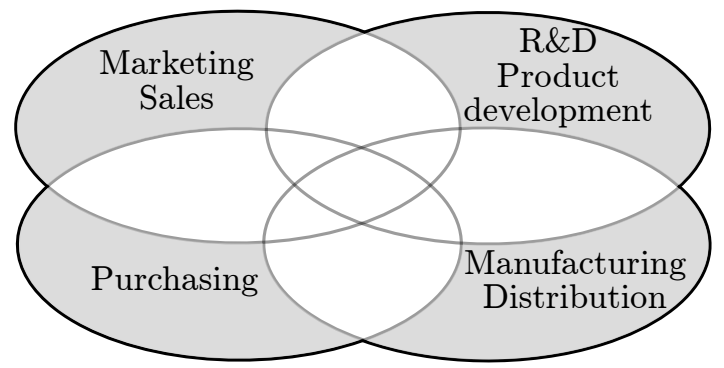

Figure 1: Functions and departments conceived as process focused collaborative units (Ericsson 1996, 2003).

The original Swedish definition of MA emphasised that the key to success is not within functional silos, but hidden at the interfaces between traditional logistics activities, marketing and product development. The interplay and interaction with marketing/sales is clear - in theory, at least. The mutual interdependency with product development was especially highlighted since a major part of the costs occurring in the logistics activities are determined by the way products are designed and engineered. Design for logistics became a key concept. The MA/logistics concept has undergone a continuous evolution based on external and internal changes, development of new tools, and new skills and talent available in companies. When the first generation of modern logistics, namely Cost Oriented Logistics, was launched during the 1960s, it focused on reducing total costs in the materials flow. During the 1970s the second generation, Revenue Oriented Logistics, focused on increasing revenue by using logistics as a means of competition. During the 
1980s the third generation, Profitability Oriented Logistics, focused on increasing profitability by reducing cost, increasing revenue and, above all, decreasing capital tied up in inventory.

The reason for the evolution of these different approaches is that during the 1960s, the main problem for Swedish industry was to provide the products to markets as cheaply and swiftly as possible. The demand for Swedish industrial products was increasing rapidly on the European market, where the distance from Sweden was a concern. The focus was therefore on cost efficiency in transportation, materials handling and warehousing. During the 1970s demand slowed down, while there was a series of oil crises, and the problem was to increase the market share in a stagnating market. Hence the focus on logistics as a means of competition to increase market share and revenue. During the 1980s the focus on sales and revenue had resulted in too much capital tied up in the flow.

These approaches were all based on the way of thinking in the industrial society at the time. Solving one problem was quite often the root of creating a new one. During the late 1980s and early 1990s the fourth generation, Time Based Logistics, and the fifth, IT-based Logistics, were forerunners of what was to come. They were explicitly process reengineering and IT focused and reflected the increasing turbulence and discontinuity of the emerging information society. The technological development and the introduction of new tools and methods enabled new approaches to the flow issue and in this way the approach was widening.

MA/logistics advocates a new perspective on materials flows, emphasising that the approach has two major concerns. The first concern lies in the management of rationalisation as a conventional, functional, department oriented responsibility, aimed at decreasing cost. The novelty in that approach was the total cost approach, which focused on costs in the entire flow rather than within functions. Efficiency by making the best use of available resources at lower cost was the goal. Transportation costs were balanced against warehousing costs, manufacturing costs against inventory costs - trade-off was the key word. The second concern is much broader and company-wide in scope, with the goal of developing a cross-functional, coordinated focus on the level of service; in other words, to reorientate the entire business to face the market and the customers. Effectiveness by addressing customer needs and demands, and measuring goal fulfilment was, and still is, the goal. Initially this too was an intra company approach, but it rather quickly evolved into an interorganisational question. Organisationally the approach became an issue of how the materials flow should be managed. Traditionally, it was managed as a series of fragmented, functionally based tasks. This often resulted in sub-optimisation and duplication of work.

The core problem in the implementation of the MA/logistics concept was the lack of coordination across tasks, functions and departments. Organisations, which are hierarchically structured and functionally oriented, often optimise individual functions and departments at the expense of the whole business and the customer. This means that problems may manifest themselves in one part of the organisation, even though their root cause remains unattended elsewhere. This results in low levels of corporate performance and even lower levels of service and customer satisfaction. Problems are simply passed from one functionally focused department to another in search of a solution. Unfortunately, performance measurement systems often increase these problems and lead to even more functional 
emphasis. The introduction of activity based costing has, however, been very helpful in implementation of the total cost concept.

Under the new MA/logistics concept, where the flow may be viewed as a cross-functional process, it is essential that previously dispersed activities should be brought together and managed in a holistic way. However, the mere introduction of a new department called materials or logistics often caused more problems than it solved. A transient structure was therefore often used initially. Key players were drawn together in multi-functional teams or groups which attempted to marshal resources so as to achieve logistics-based objectives by focusing on inter functional processes.

The notion of materials flow highlights the importance of business processes as a sequence of activities whereby value is created and costs incurred. This idea has many implications, such as, for example, pointing out the ways in which the level of service and added value may be enhanced at lower cost through process reengineering.

The successful management of interrelated processes requires a fundamentally different approach to planning and execution. To maximise customer value at the least cost to the business frequently requires a rearrangement of the sequence in which tasks are performed. In some cases these tasks are eliminated or combined with other tasks, or performed in parallel (Ericsson 1976). Implementation of the MA/Logistics concept in business indicated quite clearly that there is real performance leverage in moving toward a flatter, more horizontal mode of organisation in which cross-functional, end-to-end work flows link internal processes with the needs and capabilities of both suppliers and customers.

Therefore, in the first book on MA/Logistics, it was highlighted that the focus should be more on processes and flows than on functional activities (Ericsson 1974, pp. 43-44): "In the future, interest will become concentrated on the various types of flow which exist within the organisations. For example, the materials flow will form the focus for decisions rather than the functionally specialised departmental activities. The flow of other resources, such as men and capital, will be regarded in the same way and the main emphasis thereby altered from vertical departments to flow processes in a horizontal direction. Similarly, the organisations will be defined in terms of information and decision systems with the result that we shall be able to observe the structure of the organisation in a different way." Figure 2 displays the manner in which flows and processes may alter traditional boundaries.

Process management and digital infrastructure enable this type of approach to organisational development. Process management is developing into an interfunctional, interorganisational and interdisciplinary approach. It is aligned with contemporary thinking in different disciplines, which provides support when it comes to implementing new flow concepts. Hammer (2001, p. 13) argues that as companies have now implemented processes within the firm, they need to integrate them between firms: "Streamlining cross-company processes is the next great frontier for reducing costs, enhancing quality and speeding operations. It is where this decade's productivity wars will be fought. The victors will be those companies that are able to take a new approach to business, working closely with partners to design and manage processes that extend across traditional corporate boundaries. They will be the ones that make the leap from efficiency to super efficiency." 


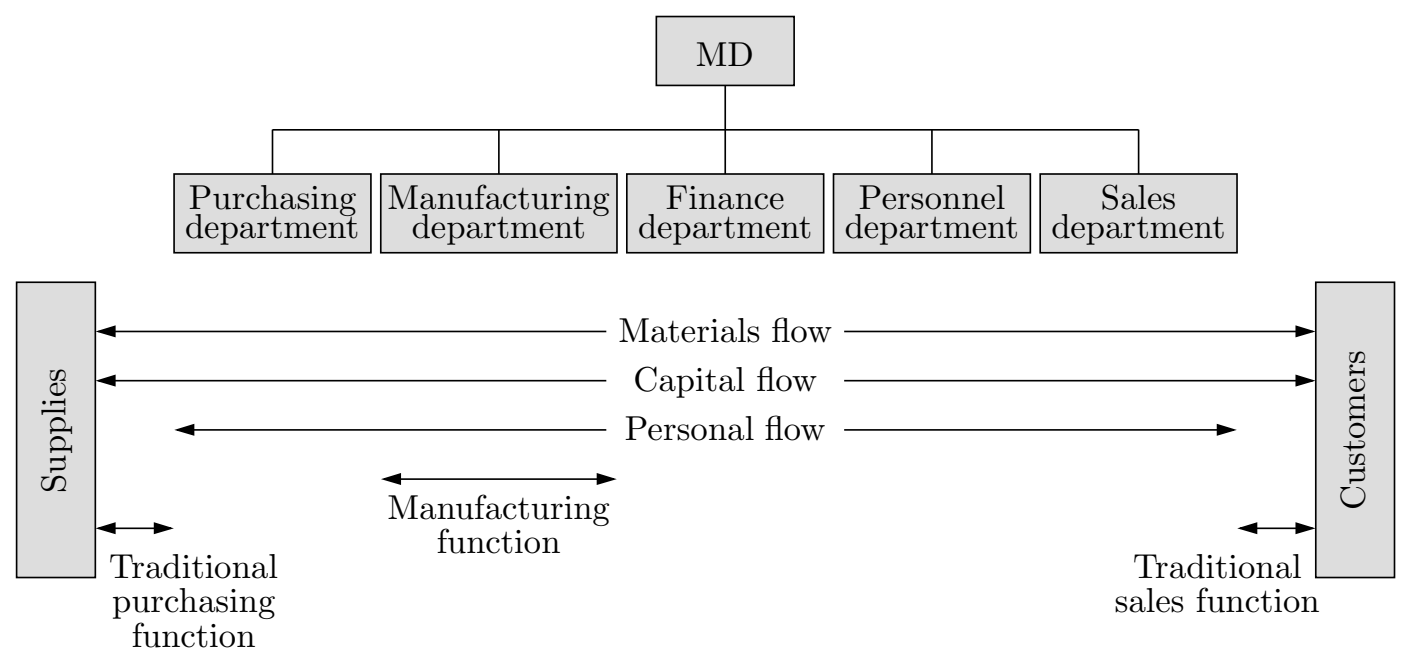

Figure 2: Flows and processes are cutting across traditional department boundaries (Ericsson 1974).

Process management and reengineering has been pointed out as the key to success for some time (Keen 1988 and Davenport 1993). However, up to now many practical applications have been unsuccessful. Several attempts at implementation of the process oriented approach in business has made it clear that an organisational change has to be accompanied by a transition process in which old habits and ways of working are replaced by new mindsets. Learning has to go hand in hand with unlearning (Ericsson 1981, 1996).

It was evident that a new tool box was required for implementation of emerging methods and techniques that promised to change the world if used properly. E-logistics was introduced as such a tool box that takes the gap between tools and visions as a starting point. The driving force is information rather than materials flow, and one of the goals is to substitute information for inventory. The concept focuses on the leverage effect of ICT and Internet technology on traditional logistics and, most importantly, it makes use of recent progress within process management. E-logistics is an enabler in simple transactions based on e-commerce, but it is also a major key to success in e-business (Ericsson 2000).

\section{E-logistics}

During the 1970s increasing competition and a slow-growing economy meant that flexibility and coordination within the whole organisation became even more important than isolated functional performance (Ericsson 1974). During the 1980s and 1990s, fast-changing markets and decreased product lifetimes highlighted not only intraorganisational but also interorganisational coordination. These new challenges required managers to rethink the way they interacted with their suppliers, other channel members, and customers.

In this interorganisational rethinking, many lessons can be learnt from the development and implementation of the early intraorganisational MA/logistics concept. An approach that organised the flow of work around company-wide processes and linked those with 
suppliers and customer requirements evolved. Ericsson (1996) states that: "Logistics is the cradle of process orientation in terms of approaches to intra- and interorganisational relationships and flows."

The vision of an almost seamless flow can only be achieved by using state of the art information and communication technology and advanced process management. The vision was created during the 1960s, but the tools to accomplish the vision were not developed until the mid 1990s. During the first five generations of logistics, up to the mid 1990s, the tools and techniques of ICT were lagging behind the visions of top management. However, from that point of view, there were more tools available than top management took into consideration (see Figure 3). As Christopher Columbus would have put it: "Man is limited not so much by his tools as by his visions" (Ericsson 2007). Figure 3 shows a rather interesting fact. During the mid 1990s, the tool curve surpassed the vision curve, which means that there were more tools available than we had visions for. For a while, it was a willy-nilly use of technology with many mistakes. The so-called "dot com bubble" was one of them. Around 2010, an intense work with visions rooted in technology started, visions were catching up and real, measurable results emerged (O'Marah and Hofman 2010).

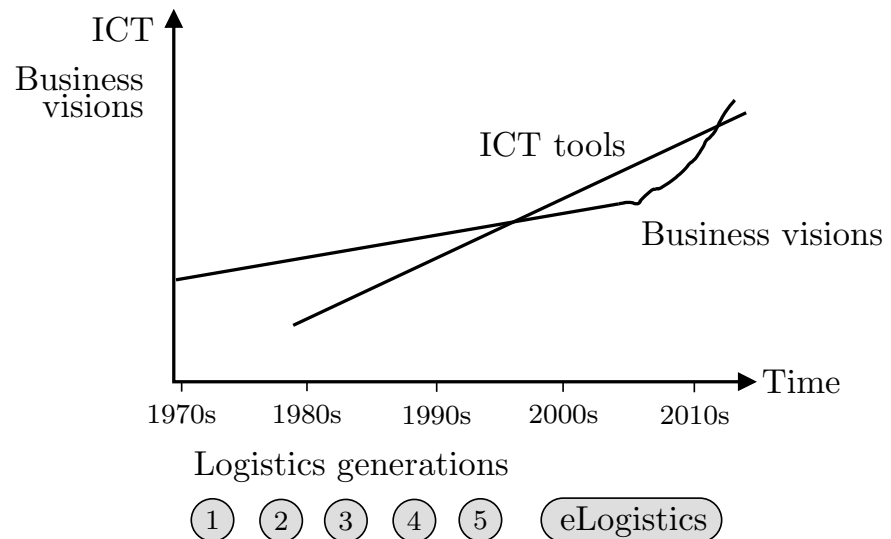

Figure 3: The interaction between visions and tools with an important intersection in 1995 (Ericsson 1996).

The rapidly increasing development of new tools and techniques, especially within ICT, initiated a wave of innovation and rethinking regarding business development. As already discussed, the MA/logistics approach started out on the operational/tactical level first by coordinating activities and processes in the internal physical flow and then by aligning administrative processes. Suppliers and customers were included in the focal system right from the start (see Figure 4).

The main focus of the logistics function was on the alignment of production and consumption systems (in a wide sense) in the operational system, as shown in Figure 5. In the early discussions regarding the evolving concept of MA/logistics, the core logistical function was defined as integration of supply and demand. This approach has been rather successful and today all logisticians can illustrate the operational system for coordinating supply and demand in terms of, for example, process maps. The global economy with increas- 


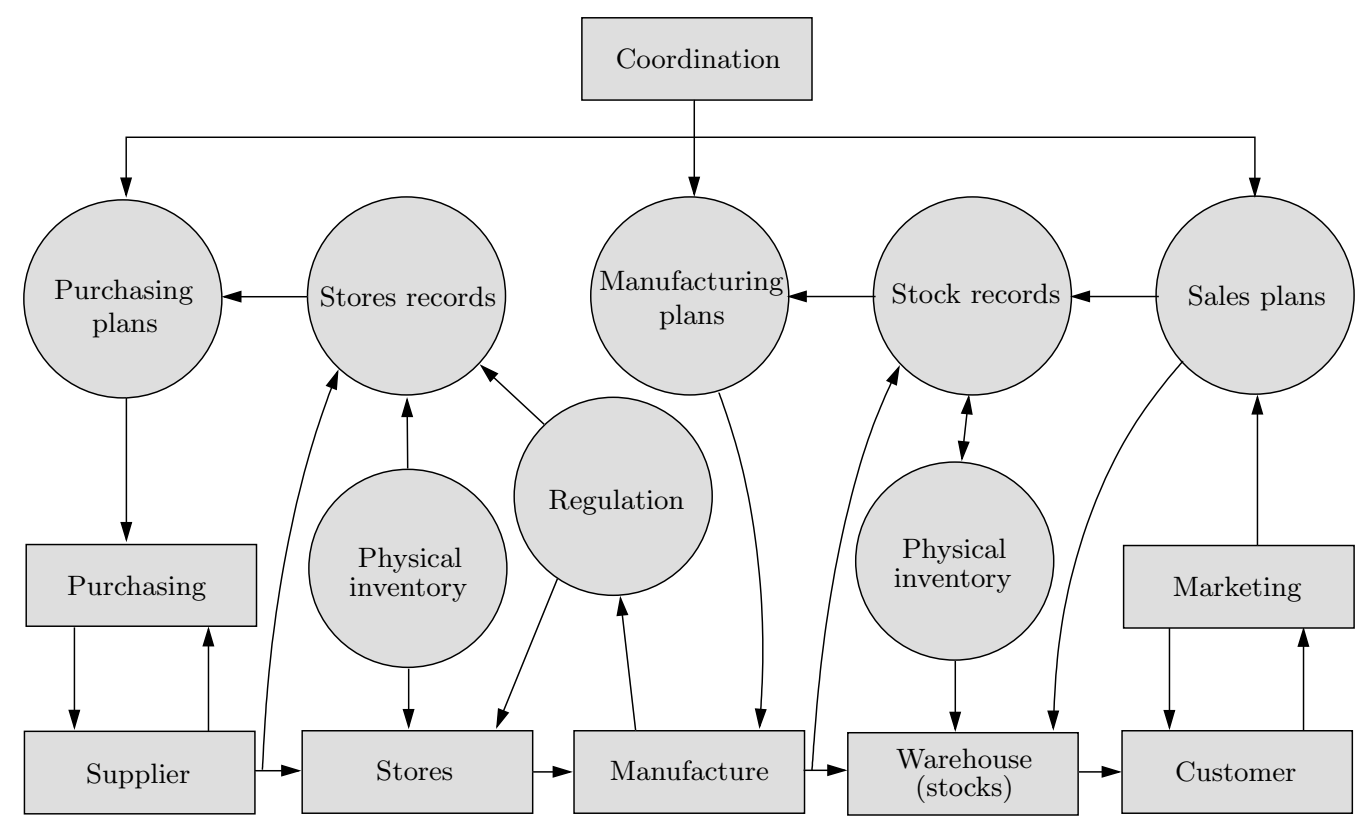

Figure 4: Internal coordination on the operational/tactical level and connections to suppliers and customers (Ericsson 1974).

ing distances between suppliers and buyers, outsourcing, etc. led to increased complexity, long and winding transportation routes, long lead times, and increasing risks in the supply system. The necessity of rethinking, reengineering and designing resilient systems became clear. This requires a shift of focus from the operational level to the strategic level.

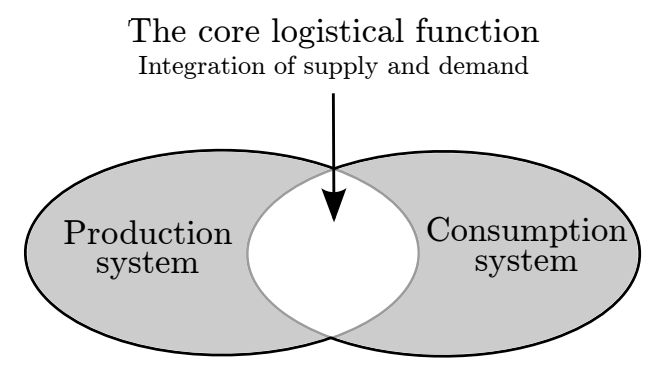

Figure 5: The core logistical function - integration of supply and demand (Ericsson 1969).

The only way to cope with this new environment was to rethink and create new business models with innovation embedded in the approach (see Figure 6). The innovation system, however, is much harder to picture and measure, but it grows even more important with increasing competition and new consumer demands. Value innovation was seen as the key to success and a vital ingredient in evolving approaches and the future development of the logistics concept (Ericsson 1996, 2000). The focus on innovation is also one of the cornerstones in DCM. 


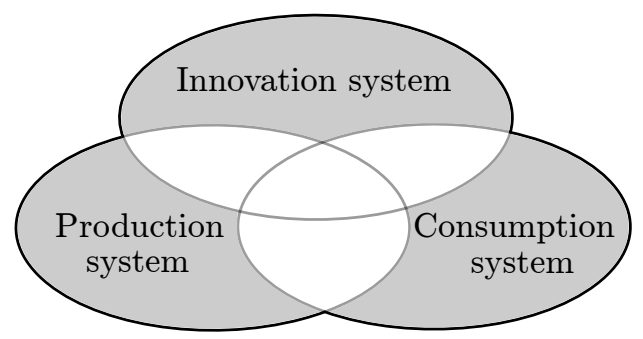

Figure 6: The innovation system as a key to strategic development of logistics (Ericsson 2000).

Application of the notion of e-logistics has made it possible to fulfil two major logistics goals:

- Efficiency was improved by doing what the company did before, but in a different way and faster, based on process improvement.

- Effectiveness was improved by doing things the company did not do before, such as offering the customer more value added products and services.

E-logistics focuses on the interfaces between Process Management, ICT and traditional logistics (as illustrated in Figure 7). The linkages have to be exploited and the areas have to be more closely aligned. E-logistics is a cornerstone in the creation of agile supply/demand chains. The alignment enables this new development and it also creates a key to implementation. The development of logistics, as described above, has provided the experience, the models and the methods for enhancing effectiveness and efficiency in increasingly complex chains and networks. ICT provides the tools and techniques that are necessary to move from materials to information flow oriented approaches, and also from SCM to DCM. ICT can also help decrease costs by reducing complexity in chain management. Many people are still involved in creating, communicating and executing inaccurate forecasts. This leads to constantly changing plans, turbulence and bull whip effects. Advanced, integrated information systems reduce the need for forecasts and at the same time they offer a better platform for building forecasting and planning systems. They also enable efficient communication of plans and exceptions in the whole chain.

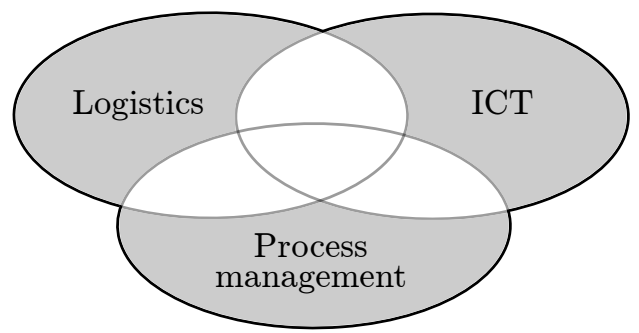

Figure 7: E-logistics, interaction and alignment between logistics, ICT and process management (Ericsson 2000).

Process management is the key to improve relationships and behaviour in order to gain a competitive advantage. ICT, in combination with process management, has a substantial leverage on logistics performance. Integration and holistics based on process orientation 
have always been key concepts within logistics. The importance of an approach where processes are mapped, simplified, integrated and "IT-fied" (in that order) has always been stressed. Identification and elimination of non value adding activities is the basis for rationalisation and cost efficiency.

The "seven wastes" have for quite some time been the starting point for elimination of non value adding activities. Today, customer perceived value is the basis for definition of what is and is not value adding. When every single step in a process is analysed with the eyes of the customer, it becomes evident what activities to eliminate.

\section{Evolution of the SCM concept}

Traditionally, economic activity has been viewed as being comprised of basic or core activities of production, distribution and finance (Shaw 1912). Distribution involved both the creation of demand through promotional effort and the logistics of making goods and services available. Distribution was separated into two distinct sets of activities called demand creation and demand fulfilment. It could also be called marketing and physical distribution. The problem was that the two branches of distribution started to follow more and more disparate routes. Today there are signs of a reunion in the DCM concept.

Heskett et al. (1964) defined logistics/physical distribution as "the movement and handling of goods from the point of production to the point of consumption or use." This may be seen as a typical approach to the physical flow during the 1960s.

The Council of Logistics Management (1986) defined LM in the following way: "The process of planning, implementing, and controlling the efficient, cost-effective flow and storage of raw materials, in-process inventory, finished goods, and related information flow from point-of-origin to point-of-consumption for the purpose of conforming to customer requirements." This is a more comprehensive management approach to the flow of materials downstream in the channel with the customer requirements as givens. At that time, it was quite common to see customers as exogenous and the focus was on fulfilling requirements as efficiently as possible. The distinction between demand fulfilment and demand creation was quite clear. The focus on management activities such as planning, development, controlling, etc. shows the similarity with the Swedish definition discussed above.

Two consultants, Oliver and Webber (1982), introduced the term "supply chain management." Around 1990, academics first started to describe SCM from a theoretical standpoint in order to clarify the difference from more traditional approaches to managing the flow of materials and the associated flow of information (Ellram et al. 1990 and Cooper et al. 1997a). Academia was therefore following rather than leading business practice regarding SCM.

An intense discussion regarding similarities and dissimilarities between LM and SCM was initiated. Cooper et al. (1997a) performed an extensive review of the literature and management practice and asked the question: "What exactly is supply chain management and how is it different from logistics management?" Cooper et al. compared the Council of Logistics Management definition of logistics with the definition of SCM developed by 
members of the International Center for Competitive Excellence in 1994: "Supply chain management is the integration of business processes from end user through original suppliers that provides products, services and information that add value for customers."

This definition highlights the shift from looking at products and information flows to focusing business processes providing products, services and information and it highlights the necessity to add value rather than just live up to requirements. The appointment of the end user as a starting point for the design of the channel is important to note.

Several other definitions also emerged. For example, the Council of Supply Chain Management Professionals defined SCM as follows: "SCM encompasses the planning and management of all activities involved in sourcing and procurement, conversion, and all LM activities. Importantly, it also includes coordination and collaboration with channel partners, which can be suppliers, intermediaries, third-party service providers, and customers. In essence, Supply Chain Management integrates supply and demand management within and across companies" (Council of Supply Chain Management Professionals 2009). This definition has a management focus and it explicitly refers to partners and the integration of supply and demand.

Stock and Boyer (2009) developed a consensus definition of SCM by performing a qualitative analysis of 173 unique definitions of the field. They defined SCM in the following way: "The management of a network of relationships within a firm and between interdependent organisations and business units consisting of material suppliers, purchasing, production facilities, logistics, marketing and related systems that facilitate the forward and reverse flow of materials, services, finances and information from the original producer to final customer, with the benefits of adding value, maximising profitability through efficiences, and achieving customer satisfaction." In this definition, the network of relationships and interdependency is highlighted.

Cooper et al. (1997a) give an excellent review of the literature and they illustrate the confusion that exists. They conclude that even though the concept of SCM first appeared in 1982, the fundamental assumptions on which SCM rests are significantly older. These assumptions include managing interorganisational operations, which can be traced back to channels research (Bucklin 1966) and systems integration research (Forrester 1969) during the 1960s, and the more recent ideas of sharing information and exchange of inventory for information (La Londe 1984).

The conclusion of Cooper et al. (1997a) was that "it is clear that there is a need for some level of coordination of activities and processes within and between organisations in the supply chain that extends beyond logistics. We believe that is what should be called SCM." They summarised some commonalities in the literature, but they explicitly pointed out that confusion exists in terms of what SCM actually is:

"It evolves through several stages of increasing intra- and interorganisational integration and coordination; and, in its broadest sense and implementation, it spans the entire chain from initial source (supplier's supplier, etc.) to ultimate consumer (customer's customer, etc.). It potentially involves many independent organisations. Thus, managing intra- and interorganisational relationships is of essential importance. It includes the bidirectional flow of 
products (materials and services) and information, the associated managerial and operational activities. It seeks to fulfill the goals of providing high customer value with an appropriate use of resources, and to build competitive chain advantages."

The gradually evolving integration is also discussed by Stevens (1989) in his four stage model of increasing integration from Stage A, complete functional independence to Stage $\mathrm{D}$, interorganisational integration embracing tier 1 suppliers and customers. According to Stevens, Stage D is more than just extending the scope of the chain alone. "It embodies a change from product-orientation to customer-orientation, ensuring that the company is attuned to the customer's requirements, and a change in the chain from the adversarial attitude of conflict to one of mutual support and cooperation." Hewitt (1994) expanded Stevens' model by suggesting an emerging new fifth stage (Stage E) which is integrated intracompany and intercompany supply chain process management. "The objective of optimisation initiatives, in this stage, is total business process efficiency and effectiveness maximisation" (Cooper et al. 1997a, p. 3).

This five stage model is very similar to the evolution of the Swedish MA/Logistics concept described earlier, and it provides an excellent background to discussions regarding interorganisational process development.

From cited statements on SCM, it appears that more functions than logistics have to be integrated internally and across firm boundaries. There is definitely a need for better integration of internal operations. New product development is possibly the clearest example of this, but also marketing, manufacturing, and finance have to be included in internal alignment (see $\S 3$ ). In addition to these internal functions there is a need to include external organisations in the product development process in order to reduce the time-to-market on new product introductions. Early supplier involvement is important, and customer and consumer involvement is necessary.

Cooper et al. (1997a, p. 3) state that

“... to implement SCM, some level of coordination across organisational boundaries is needed. This includes integration of processes and functions within organisations and across the supply chain. A driving force behind SCM is the recognition that suboptimisation occurs if each organisation in the supply chain attempts to optimise its own results rather than to integrate its goals and activities with other organisations to optimise the results of the chain. Organisational relationships tie firms to each other and may tie their success to the chain as a whole."

This statement highlights the fact that it is necessary to look at the chain from a holistic point of view and abandon the traditional "focal company" approach.

One central question is how to integrate the supply chain. Cooper et al. (1997b) identify four possible means of managing the integration of a supply chain, namely dyadic, channel integrator, analytic optimisation, and keiretsu. A dyadic approach concentrates on one level up or one level down and is often a starting place for developing an integrated supply 
chain. The other three can go further up/or down the supply chain. The method of management differs depending on the relative strength of the supply chain members and use of computerised models such as analytic optimisation.

With reference to several authors, Cooper et al. (1997b) states that

"... the importance of building and managing relationships among members of the supply chain has been addressed by many authors. An integrated supply chain of partners without common ownership must be managed in a different manner from that of a single monolithic bureaucracy. Different forms of relationships are appropriate and not all links in the supply chain need to be partnerships. SCM partnerships will likely involve more processes and functions than integrated logistics management partnerships."

The mentioning of different forms of relationships and management issues are especially important for the discussion of DCM.

A literature review highlights two significant changes (Cooper et al. 1997b).

"First, today's widely acknowledged and implemented process-orientation of business work activities de-emphasise the functional structure within and between organisations. Second is the significant change in the perception of SCM as being more than just logistics. It can be the management of all business processes."

Croxton et al. (2001) state that

"Increasingly, SCM is being recognised as the management of key business processes across the network of organisations that comprise the supply chain. While many have recognised the benefits of a process approach to manage the business and the supply chain, most are vague about what processes are to be considered, and what sub-processes and activities are contained in each process, and how the processes interact with each other and with the traditional functional silos."

The shift from functions to processes stresses the necessity of identifying and defining core interorganisational processes. Hewitt (1994) found that executives identified up to fourteen business processes and Cooper et al. (1997a) presented seven processes.

In recent years the notion of DCM has emerged as another means of looking at chain activities. Despite the fact that DCM is a relatively new concept, it has already been defined in many different ways. A distinction may be made between two views of DCM, one wider and one more restricted. In a broader sense, Selen and Soliman (2002) have defined DCM as "a set of practices aimed at managing and coordinating the whole demand chain, starting from the end customer and working backward to raw material supplier." It requires turning the supply chain on its head, and taking the consumer as the starting point rather than its final destination. The view of the consumer as an integral part of the chain is perhaps the most important issue in the shift from SCM to DCM. 
De Treville et al. (2004) criticise these broader views because they imply that the term demand chain could effectively replace supply chain, a change in nomenclature which they see as undesirable. Hence, they propose a narrower definition of DCM. Based on the distinction between the efficient physical supply and the market mediation roles of supply chains proposed by Fisher (1997), De Treville et al. suggest restricting the term to "market mediation supply chains." In these responsive demand chains for products with innovative demand, supply chain efficiency is traded off for customer service. Also, De Treville et al. define demand chain as a supply chain that emphasises market mediation to a greater degree than its role of ensuring efficient physical supply of the product.

Selen and Soliman (2002) highlight the holistic view of the chain when DCM is defined as extending the view of operations from a single business unit or a company to the whole chain. Essentially, DCM is a set of practices aimed at managing and co-ordinating the whole demand chain, starting from the end customer and working backward to raw material suppliers.

Heikkilä (2002) proposes that supply chain improvement should start from the customer end, and that the concept of SCM should be changed to DCM. DCM highlights the need for good customer-supplier relationships and reliable information flows as contributors to high efficiency.

The most recently introduced approach of DCM attempts to capture the proposed synergies between SCM and marketing by starting with the specific customer needs and designing the chain to satisfy these needs, instead of starting with the supplier/manufacturer and working forward (Heikkilä 2002). Such an integration seems mandatory in today's marketplace, where customers benefit from having real-time access to their accounts, making real-time changes in their customised product configuration and communicating their individual service requirements.

The evolution of the SCM concept, as described above, demonstrates the shift from focusing a single process flow of logistics to focusing on several functions and processes. Cooper et al. (1997a) summarise that "... from the above discussion, it seems clear that there is a need to expand and re-conceptualise the definition and understanding of SCM. The new vision of SCM embraces all business processes cutting across all organisations within the supply chain, from initial point of supply to the ultimate point of consumption." This statement shows that SCM is an all encompassing concept covering everything. The problem is that if the concept covers everything, its usefulness is very restricted.

In all the different definitions of logistics, SCM and DCM, there is a striking lack of reference to the necessity of considering the chains from the point of view of how they are structured and organised, what type of relationships exist and the interdependence that occurs. This was one of the major issues in the marketing channel literature. If the concepts of LM, SCM and DCM are discussed in terms of types of relationships, dependence and interdependence, a much clearer view of when and how they should be used emerges. The notion of business logistics evolved during the 1960s in order to fit the then existing environment. The marketing channel consisted of rather loosely connected companies working autonomously. The focus was on efficient physical flows in rather short termed relations. 
When the market and competitive situation became tougher during the 1980s, there was a need for integration of more than physical flows across company boundaries and the SCM concept was developed. Competition forced a closer alignment between demand creation and demand fulfilment.

According to Christopher (1992), "leading edge companies have realised that the real competition is not company against company, but rather supply chain against supply chain." There is a need for a more holistic approach to the marketing channel and focus on partnerships and interdependent relations. This is where DCM fits in. DCM is not a replacement of SCM, it is one very distinct set of relationships (partnerships) that fit into the broad concept of SCM. The advantage is that DCM, in this interpretation, is quite well defined and useful in practical applications.

In order to systemise and structure the approach to the SCM concept and provide a scientific and sound basis for development of the DCM concept as it is defined here, a rather thorough review of the marketing channel research is provided. The discussion is based on Ericsson (1976).

\section{The evolution of Vertical Marketing Systems}

MA/logistics is a pragmatic and company oriented approach focusing on practical, measurable results, but changing markets and consumer requirements have shifted the focus of competition from company versus company to channel versus channel. This has increased interest in interorganisational relationships and induced a renewed and intensified interest in classical marketing channel research.

There is a lack of consensus on the definition of the concept of SCM, and it is used to cover all types of relationships from very loose coalitions to stable, long term partnerships. This may be one of the major problems both in advancing theory building regarding the concept and in measuring results from implementation.

During the 1960s and 1970s, there was a similar discussion regarding marketing channels. These discussions and research resulted in a rather pragmatic and practical distinction between various types of channel relationships. A revival of that thinking is very useful for further development of the logistics, supply and demand chain concepts. The DCM concept, as it is used here, builds on what was then called organised vertical marketing systems. This holistic approach to the marketing channel and the perception of channels as "open, organised behaviour systems" was one of the main issues in the classical market channel research during the 1970s. These concepts and approaches are now reborn.

During the 1970s, marketing channels, as well as design and development of vertical marketing systems, was a popular subject within research. That area was chosen for my PhD thesis, with the following motivation (Ericsson, 1976, p. V):

"Increased interdependence among firms within the channel, and between channels as units of competition leads to increased interest in interorganisational management, stressing the concept of cooperation and conflict. Some marketing channels can be conceived as rather loose coalitions with high degree 
of conflict and rather low degree of cooperation, but others are more integrated and 'organised'. Hence, a distinction between marketing channels can be made in terms of 'degree of organisation'."

Vertical marketing systems (VMSs) are in a scientific way defined as "highly organised systems which can be perceived as sets of objects interacting with each other to achieve common purposes." This concept is the basis for the notion of DCM as discussed here.

During the 1970s, action research was performed in the building materials sector. These investigations and the issues encountered highlighted the necessity of a more conceptual approach to marketing channels and some models were constructed in order to design further empirical studies. One of the issues was the difficulty in implementation of "rational" solutions. For example, efforts to increase transportation efficiency through improved storing capacity and the use of common distribution centres ran into practical difficulties. The main reasons for this was the lack of a common language to discuss logistics efficiency and the difficulties of setting a "fair price" on task performance.

The problems of agreeing on the benefits coming out of joint efforts, and the way to share them, were evident. Even decisions with a major impact on profitability and competitive strengths were based more on political and social reasons rather than on economic reasons. This kind of decision-making is difficult in an interorganisational setting, but they are also difficult in an intraorganisational situations as has been verified in many recent studies.

The empirical studies showed the necessity of analysing how to design, develop and manage interorganisational systems. VMS, and marketing channels in general, were in need of conceptual as well as empirical investigations, and an interest in interorganisational approaches to marketing channels were increasing.

I started out as a more traditional, analytic researcher by considering functions within focal companies, even though my licentiate thesis had a "boundary spanning" approach. It was concerned with the choice of a marketing mix in a set of manufacturing industries (Ericsson 1965). My parallel work as a consultant resulted in a series of books on purchasing, marketing, physical distribution, and manufacturing. They highlighted the changing role of functions and departments in the "new" evolving market environment. This functional start and the problems with "silo mentality" and suboptimisation that were highlighted initiated an interest in boundary spanning approaches, first internally and then with suppliers and customers in the evolving logistics systems as discussed above. The first book on this new topic "Materials administration/Logistics" was published in Swedish in 1969 and in English in 1974.

The VMS study was based on my earlier investigations within the areas of industrial marketing, procurement, physical distribution and logistics. Management of interorganisational systems of the VMS type was of increasing importance. Coalitions of firms, both horizontally and vertically, were becoming a more common feature of the management environment (Ericsson 1976, Chapter 7).

The approach in my doctorial thesis was the result of the convergence of three conceptual trends:

1. The marked interdependence of objects operating within marketing channels, 
2. The conception of channels as social systems, and

3. The analysis of behavioural as well as economic relations in such systems in order to yield managerial implications regarding design and development of VMS.

These conceptions and trends represented one of the two reasons for initiating the study. The other reason was some "empirical" quests for the analysis of marketing channels and the design and development of VMS. The shift in focus from functional and departmental to company wide and later interorganisational approaches highlighted the need for a different and more holistic approach.

The following quotation from the background and purpose of the study is interesting for today's discussion of SCM (Ericsson 1976, p. 5).

"Marketing practices are changing and there is a steady increase in the interdependence between firms within marketing channels. This leads to increased coordination between suppliers and customers, and also to efforts at coordination of the marketing channel as a whole. The increased coordination can take various forms, from rather weak cooperation in terms of blanket ordering, via stockless buying, systems contracting, and subcontracting to outright ownership integration. In this way, there is a shift from a 'horse-trade' type of short term business relations to a more stable type of relationship."

Different concepts and relationships in the marketing channels as presented by several researchers provide an important background to and frame of reference for the discussion. Ericsson (1976, p. 46) continues: "Alderson's concept of organised behaviour systems is similar to Bowersox and McCarthy's concept of "planned vertical marketing systems'." They state that "an important distinction should be made between channel systems and planned vertical marketing systems. Not all channel systems have members who see themselves as part of the system" Bowersox and McCarthy (1970, p. 57).

Bowersox and McCarthy (1970, pp. 57-58) also discuss "administered channel systems" as systems where the manufacturer or the middleman has made a commitment to attempt to tie the system together, but where the other members of the system simply joined in if they felt that it was in their current interest. In contrast they state that "a planned vertical marketing system, in comparison to a traditional or administered channel system, is one in which both the manufacturer and the middleman (or middlemen) have made a commitment to the channel system - a commitment to jointly provide something to some target market." Bowersox and McCarthy (1970, p. 56) also state that "planned (or more integrated) channels seem to operate at from one-third to one-half of the cost of channels using traditional methods. Nevertheless, some new firms persist in following the evolutionary path and currently are adopting the methods and organisations of obsolete systems."

Ericsson (1976, p. 45) summarises: "Hence, it can be concluded that what is conceptualised as marketing channels range from very loose coalitions to highly cohesive systems. The widespread existence of uncoordinated marketing channels has, as mentioned, inspired McVey to question if channels are what the textbook says and not simply a sequence of consecutive markets where nobody looks more than one step ahead. However, even in 
such loose coalitions there is interaction and interdependence because transactions must be consummated, and the number of more integrated channels grows rapidly because of competitive forces."

Ericsson (1976, p. 43) continues. "A marketing channel is a political as well as an economic system in at least three senses:

- Some or all of its participants may achieve a high degree of group solidarity so that they bargain with other social systems on a collective as well as individual basis.

- The marketing channel is a political system because the participants strive to control the behaviour of other members. An understanding of power alignments is necessary to the development of a theory of marketing channels.

- A channel is a power entity because the participants constantly bargain for favourable terms of trade - a process that involves strategy, bluff, subterfuge, and other political devices. Hence, conflict as well as cooperation, is characteristic of most inter firm alignments."

Ericsson (1976, p. 30) made a distinction between:

1. Marketing channels, which may be rather loose coalitions including the consumer,

2. Commercial channels, which may also be rather loose coalitions, but excluding the consumer,

3. Vertical Commercial Channels (VCCs), which may be rather loose coalitions ranging from the whole channel to segments of the channel, and

4. VMSs which are highly organised, stable coalitions with the aim of achieving a common purpose.

The need for coordination was also highlighted by the development of more "value added" products. "The supplier's selling offer (the product and service) is usually manydimensional and includes not only hardware but also software in terms of 'additional services' which tend to increase product differentiation and make comparisons between suppliers hard to carry through" (Ericsson 1976, p. 12). Product and service offer highlight the importance of increased cooperation and alignment both internally and externally, and was expressed as follows by Ericsson (1976, p. 14):

"The product offer of the seller includes dimensions that can only be worked out in close cooperation between several departments within the firm; especially between purchasing, engineering, production, marketing, and logistics departments. Furthermore, the product offer is often worked out in interaction between seller and buyer in each instance. This involves several departments on the buyers as well as the sellers side, which means that certain individual relations may highly affect goal-fulfilment of sellers as well as buyers. However, subgoals for different departments may be conflicting, and in that way be jeopardising total company success."

Customised product and service offers have to be developed in close cooperation between seller and buyer, which makes it necessary to have a frame of reference for the approach. 
The concept of "perceived customer or consumer value" has proven to be such a uniting concept.

\section{Perceived customer value}

It is often stated that customers should not only be satisfied, but that their expectations should be exceeded. In order to exceed customer expectations, they first have to be defined and described in an operational way. Using the notion of perceived customer value is one way of achieving that. The foundation of the concept is the fact that the boundaries between physical products and accompanying services are blurring, and increasingly so in the digital economy.

The offer to the customer consists of "a bundle of utilities," i.e. a mix of products and services (Ericsson 1976, 1996, 2000). At the centre is the tangible product that can be described in engineering terms in other words: the traditional "conformance to specifications." The core is surrounded by a set of intangible services such as logistics, availability and technical support (see Figure 8 (a)).

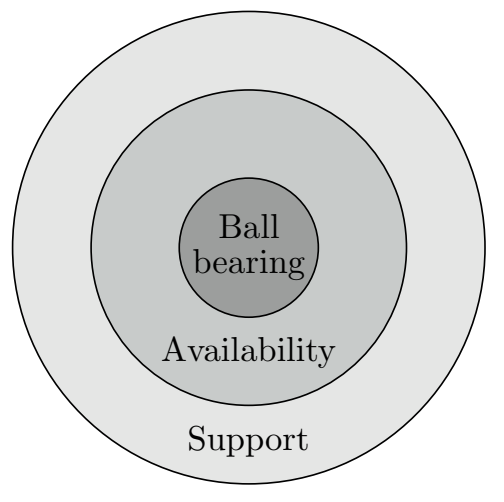

(a) The SKF offer of products and services

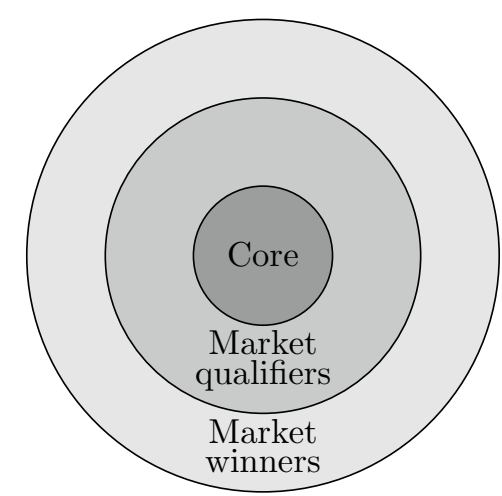

(b) The core product and value added services

Figure 8: An illustration of the notion of "perceived customer value" (Ericsson 2003).

The concept of value is customer-specific and essentially subjective to the customer. It represents the perceived benefits that the customer receives from ownership or consumption of a product or service. This value may be given by $T Q / T C$, where $T Q$ denotes total quality as perceived by the customer and $T C$ denotes total costs as perceived by the customer.

In order to make this definition operational, it is necessary to define total quality. In several practical situations it has proved useful to define two sets of quality that refer to the tangibles and intangibles mentioned above. At the centre is a "hard core" of objective and engineering facts, especially when it comes to physical products. This is the core quality, which is surrounded by several layers of basic and added values that make up the fringe quality. The first layer of basic values defines the market or order qualifiers. The second layer defines the market or order winners (see Figure 8 (b)). 
The notion of total cost is also subjective, depending on, for example, the way the customer values his own time and efforts. IKEA built its approach on the fact that to certain customers the value was higher in buying "knocked down" products and assembling them rather than buying ready-made furniture at a higher price. It all boils down to a subjective valuation of the customer's own time and efforts.

The core and fringe approach and the concept of perceived customer value was used at SAAB-Scania during the mid 1980s as a means of focusing efforts on the total quality concept when its "One step ahead" program was launched. In 1985 it was also used in Volvo of Australia to illustrate and emphasise the "total experience" of the car. These applications showed very explicitly that different customers have different requirements and demands.

Different products require different logistics systems. The real challenge for logistics today is to design customised delivery systems. Customised delivery systems do not only refer to the physical delivery of products or the presentation of services, but also to the marketing channels employed, the use of the Internet, the flexibility of response, the linking of logistics and information systems, and so on. The design of customised delivery systems is a critical means of engineering stronger linkages between the customer's demand chain and the vendor's supply chain.

For commodities, the solution might be a lean supply chain based on rather accurate forecasts. For innovative products, such as fashion wear, the best match might be a responsive supply chain based on agility and rapid reaction on changing conditions (Fisher 1997). The same product might have different systems requirements based on the use of the product. Original Equipment Manufacturers (OEM's) customers have one type of requirement on the system, wholesalers another and spare part users a third.

SKF, the Swedish ball bearing company, takes this into consideration and defines perceived customer value for specific segments. Unique channels are then identified to fit end user requirements, and the efforts are managed by a "channel captain" (see Figure 9). In order to succeed, all the activities leading to the outcome have to be coordinated, integrated, and synchronised. This requires process and systems integration, end to end. The hit has to be achieved at as low a cost as possible for the customer as well as for the supplier. The final supplier cannot achieve this on his own, it has to be part of a whole, namely the integrated channel.

The definition of organised VMS developed in my thesis (Ericsson 1976) has been used as a frame of reference in my later work both as a consultant and researcher. It is easy to see the resemblance between the discussions concerning marketing channels and today's discussions regarding SCM. The DCM concept, as it is used here, is a further elaboration and development of the VMS concept.

DCM is focusing on the structure and behaviour in value chains based on trust and mutual interdependence to create superior perceived consumer value. With this frame of reference, the demand chain may be defined as an integrated and aligned chain built on partnership and mutual interdependence aiming at creation of a unique competence to identify and satisfy customer perceived value, while DCM may be defined as the effort to create, retain and continuously develop a dynamically aligned demand chain. 


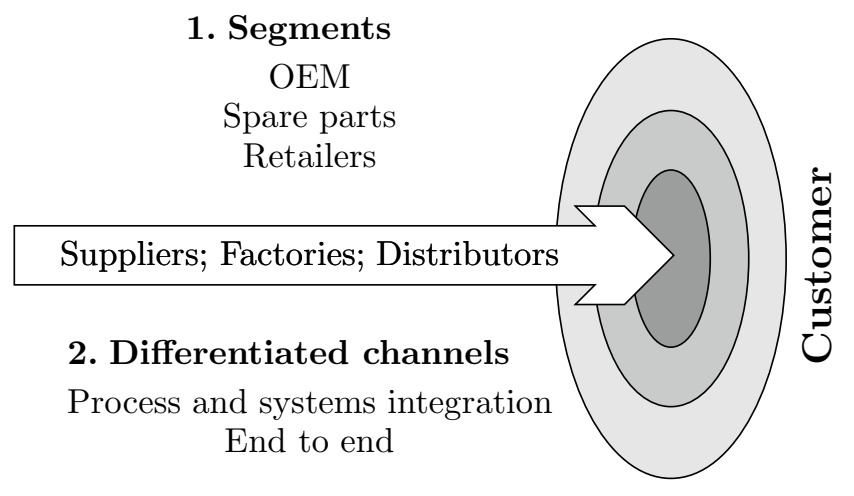

\section{Relationship management}

Internal and external

Figure 9: The SKF channel concept (Ericsson 2003).

\section{Interorganisational core processes}

The question is how to transform strategic concepts and ideas into practical implementation. E-logistics can provide the bridge between visions and tools. Implementation of the SCM concept is based on development, integration and alignment of core processes in the network. The importance of using a process approach is stressed, but discussions regarding which processes to focus on, which sub-processes and activities to include, how the processes interact with each other and with traditional functions and departments are rather vague or nonexisting.

The core process orientation suggested here is closely related to the first MA/logistics approach which focused on the interfaces between functions and departments such as R\&D and engineering, marketing, purchasing and manufacturing/distribution. The discussion in $\S 3$ shows how and why functional and departmental activities were grouped together and united under different types of boundary spanning flows and processes.

The importance of shifting from a functional to a process orientation is highlighted by Hammer (2001) who states that "the key differences between the traditional functions, which have similar names in some cases, and the process approach are that the focus of every process is on meeting the customer's requirements and that the firm is organised around these processes. The customer focus has not always happened in companies where the silo mentality has prevailed."

Several different sets of processes and activities are included in SCM, as discussed above. Focus on too many processes quite often lead to confusion and problems in implementation. One of the keys to success lies in simplification. Therefore, four core interorganisational processes in industry should receive focus. These processes have a direct and understandable relation to traditional functions and departments that make them easy to use in practical applications (Ericsson 1996). The four processes are Time to Cash (TTC), Customer Creation and Retention (CCR), Supplier Creation and Retention (SCR) and Time to Market (TTM). At the interface of all four processes lies a fifth process, the DCM process, that aligns key parts of the other four processes in order to create an interdependent, 
partnership based chain, i.e. the demand chain. The integration of these five processes are shown in Figure 10.

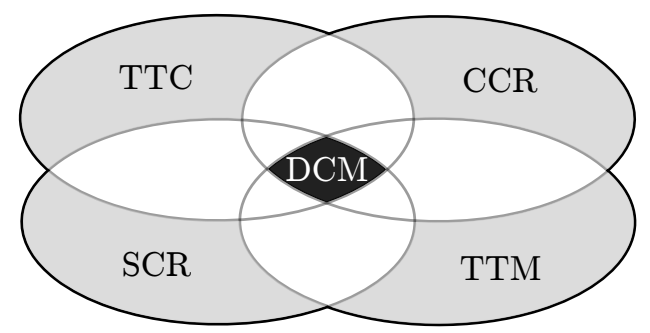

Figure 10: Four interorganisational core processes and demand chain management as a fifth intersecting process creating and interdependent partnership.

\subsection{Time to Cash}

The first process is TTC, which may be seen as the fundamental and basic process in MA/Logistics. The TTC process is at the heart of traditional logistics, and it focuses the order fulfilment process from initiation of the order to the delivery to the customer. This process, which used to be called Time to Customer, builds on integration and alignment of purchasing, production, logistics, and marketing plans and actions first internally and in the second step also externally. The inclusion of the invoicing and payment activities was the reason for the change of terms from Time to Customer to Time to Cash.

There are different kinds of members in the network. With the first (key partners) there is a close and intimate relation, with the second there is a more standardised way of interacting, and with the third, there is just a transactional, ad hoc relation.

The demand chain approach focuses on the interplay between key partners. To build a demand chain it is important to analyse and decide which companies are going to be strategic partners and which ones are going to be treated in a more standardised way as suppliers and customers. The purpose of the demand chain is to create a unique competence and reduce the costs in the whole chain with this as a given. Therefore, it is important to develop and maintain close relations with key partners and to continually develop and improve the processes. Development and operation of the network is decisive for effectiveness, efficiency and costs in the network. It is important to decide about what kind of relations to have with different members of the network. Some are vital for the survival and achievement of the goals, while others are easily replaced.

\subsection{Customer Creation and Retention}

The second core process is CCR, and it includes subprocesses such as Consumer/Customer Insight, Customer Relationship Management, Customer Service Management and Returns Management. The CCR process consists of two closely related parts, namely customer creation and customer retention. This reflects the fact that marketing has two main concerns: 
1. The creation process focuses on transactions and the initiation of customer relationships. This is the traditional marketing concept based on the marketing mix and exchange.

2. The retention process focuses on keeping and developing relationships with the customer and their transfer up the ladder from customer to partner. The retention part is closely related to the activities after the actual transaction. In other words, returns management, after sales, spare parts management, follow-up and continuous improvement.

CCR provides the structure for how customers should be created, developed and retained. In a DCM approach, key customers and other customer segments are identified based on the companies' overriding visions and goals. Customer teams design and develop the product and service offers (the value packages) that meet the needs and wishes in different segments. Value packages are based on segmentation and definition of perceived customer value in the different segments. Deep and thorough customer insight is transformed into products and services with a high perceived customer value.

A customer's demand chain may start with purchasing, followed by inventory control and scheduling. This means that there are three alternative connections between a buyer and a seller: offer to purchase, offer to inventory and offer to scheduling (Ericsson 2003).

Transactional marketing aims at developing the right offer for the customer's purchasing people, that is, giving an offer to purchase. But it is possible to deepen the relationship by an offer to inventory by, for example, automatic refill of stock, or taking care of the customer's warehousing through Vendor Managed Inventory (VMI), or even going one step further into the customer's own scheduling and co-plan the performance. When the order penetration point is moved further into the customer's processes, the relationships become deeper. In this way time is gained, which makes it possible to move the supplier's customer order point from deliver to order to make to order. This is a necessary step to achieve increased profitability. Early information creates the necessary time gain, and opens a window of opportunities for flexibility in planning and execution of supply chain activities.

It has to be noted that the Perceived Consumer Value (PCV) approach discussed above is used as the starting point and the bridge in customer as well supplier relations. For example, it is a very useful tool in creation of Collaborative Planning, Forecasting and Response (CPFR) approaches. The customer teams work with key accounts to improve processes on a continual basis, reduce volatility and eliminate nonvalue adding activities. Performance reports are developed to measure profitability in different segments, to define win-win situations and provide guidelines for sharing of results.

The purpose of CCR is to identify customer segments, create criteria for categorisation of the customers and provide guidelines for how the value packages should be developed and delivered. On the operational level, customer segments are defined and the value packages are differentiated, designed and delivered.

Returns Management (RM) is a vital and critical part of CCR. RM is important, not only to reduce costs in the reverse flow, but also to maintain and improve customer relations. RM provides the opportunities to deepen customer relations and create insight 
into customer needs, wishes, problems and opportunities (Hjort 2010).

\subsection{Supplier Creation and Retention}

SCR is the third core process, and it is the mirror image of CCR. The supplier market is just as critical and important as the customer market, and price and low purchasing costs are no longer the most important issues. Just as companies have to develop and manage relations with their customers, so also do they have to manage supplier relations (see the SKF discussion above).

SCR is the process that defines how companies interact with their suppliers. Suppliers have to be segmented, and close and intimate relations have to be developed, maintained and continually improved with a small set of key suppliers that are included in the demand chain. The rest have to be handled according to more traditional methods.

Key partners deliver a value package that is designed and developed in close cooperation between the supplier and the buying company. The supplier process team starts out from the company's overriding strategies, production and purchasing strategies, and, in cooperation with the supplier, value packages that are key to success now and in the future are developed. Key suppliers work with highly customised value packages, while the other suppliers work with more standardised packages. Key supplier relations also have to be built on a win-win situation and criteria for continuous improvement have to be defined and adhered to.

A supply chain may include purchasing/sourcing, manufacturing, warehousing, and distribution/sales. This means that the contact with the customer can take place on at least four different levels, namely Deliver To Order, Pack To Order, Make To Order or even Source To Order. The first is the traditional transaction based contact between the customer's purchasing function and the supplier's sales people which is followed by a delivery of the order. The next contact may also be based on customised packaging for an order, through direct order production, or by monitoring sourcing. In most cases, moving the customer order point upstream means increasing leadtimes. This has to be compensated for by gaining time and by moving downstream in the demand chain, in other words by getting early information.

\subsection{Time to Market}

TTM is the fourth important process and it concerns product development and commercialisation. To develop products and get them out on the market rapidly is decisive in most industries. Dell highlights this by calling their process Time to Volume.

A focus on leadtimes and synchronisation of activities is the main theme in the TTM approach. Just like the concurrent engineering and concurrent design it stresses the fact that product development activities cannot be performed in sequence with walls and moats between the functions. Walls have to be torn down and moats bridged in order to perform activities in an integrated and often parallel way. The development of concurrent engineering and a focus on TTM has increased and hastened the development of interfunctional cooperation in product development. 
One of the main ideas of DCM is to integrate key customers and suppliers in the process in order to improve and to reduce lead time in product development and commercialisation. When product life times are reduced, products have to be developed and launched in a much shorter time in order to maintain and improve competitive power. This means that the necessity for cross functional and interorganisational integration and cooperation increases. Concurrent design is a rapidly increasing concept aimed at handling this requirement. The fashion industry is a very telling example of this. Zara is an example of a company that has reached success by involving people from the right departments and partners at the right time.

To create an effective and efficient supply chain it is necessary to have alignment and interplay between the four core processes. These four core processes span the whole flow and they cut across companies and internal functions within companies. Activities within several functions and departments are involved, but the processes are boundary spanning. In a SCM approach all processes have to be taken into account, but the relative importance of the processes and activities can vary.

The description above takes its starting point on a focal company level, but it is important to stress that implementation is based on a holistic view of the interorganisational processes. Within companies it may be possible to rely on traditional management, but in the network hierarchical management is impossible and governance has to be based on trust and cooperation with a common view and interest as the point of departure.

\subsection{The DCM process}

The examples above show very clearly that the key issue for success in DCM is to create trust and build lasting relationships. All four interorganisational core processes have to be aligned and balanced in order to create effective and efficient SCM applications.

To achieve effective DCM there is a need for a fifth integrative, aligning and collaborative process, namely the DCM process. The DCM process focuses on the relations and interplay between key partners (as opposed to all partners) in the chain from consumers to raw materials suppliers. The process aligns and synchronises key customer demand with the focal company and its key supply partners. The issue is to establish a unique competence and capabilities to create truly customised PCVs. This fifth process is what distinguishes DCM from SCM in its focus on key players and innovation and rethinking, not only in order to improve efficiency and effectiveness in existing operations, but also to find new areas for development and possibilities. Kim and Mauborgne (2005) challenge companies to break out of "cut throat" competition on the "red ocean" and create a market space of their own, "the blue ocean," where competition is irrelevant. In the red ocean's industry boundaries are clearly defined and accepted, and the rules of the game are well known. The key is to be better than competition and increase market share. A blue ocean, on the other hand, is an unexploited market where you can create new demand and profitability outside of traditional industry boundaries. This is exactly what the most successful companies have been doing in recent years. DCM, if intelligently applied, is the key to entering the blue ocean domain.

As mentioned before, it is not possible for the focal company to keep close and profitable 
relationships with all members of the network. The trick is to choose and align partners that together create a distinctive competence and a unique PCV that no one can create on its own. This distinctive competence is the mere foundation for DCM and it builds on a strategic positioning enabled by the interplay and union of the core processes of CCR, SCR, TTM and TTC.

The purpose of DCM is to create a distinctive competence that in a decisive way improves the strategic position within a new segment. This competence cannot be created by a single company in the chain, which means that the members are mutually dependent of each other. Leadership therefore has to be based on governance and the type of relationships described in the SKF case. Within SCR this type of behaviour is not uncommon, but within CCR this kind of very close connections with the consumer has not been so common. One of the reasons for this is, of course, that it is much harder to keep close contacts with a large number of consumers. However, technology development, social media, etc. make it possible to collaborate with segmented groups of consumers. Consumers today are more knowledgeable and unfaithful towards suppliers and brands than ever before. Social media spread "word of mouth" in seconds to millions of potential users. For good and evil.

In classical marketing channel literature, the consumer was not included in what was called "the commercial channel." Today, consumers are integral and important parts in the DCM, and consumer focus is the starting point for design of the whole channel. Consumer insight is created by close relations with the consumer where not only quantitative, hard data but also qualitative, soft data are used as launching pads. Zara has been mentioned as an example of this, but also Electrolux and Ericsson have well developed processes for creation of consumer insight.

\section{A portfolio of relationships}

As discussed above, companies are working with a portfolio of relationships from transaction oriented contacts via traditional supplier and customer relationships to deep, competence and interdependence based, long term partnerships (i.e. demand chains). The term supply chain is used to denote all of these relationships, while the term demand chain is used only for the long term partnerships (i.e. organised vertical marketing channels).

Today's technological development, the shortening of product life-cycles and increasing consumer demand for more and different goods, forces firms to seek partnerships in order to cut costs and reach out to customers. In the past, the corporate decision-making process was generally "optimised" within a single company through a cross-functional integration. Today, the situation has changed and individual companies "no longer compete as solely autonomous entities;" instead "internetwork competition" is now one of the main characteristics of business (Lambert and Cooper 2000).

This has given rise to different forms of integration, such as SCM, that highlight the need and advantages of spanning boundaries between entities in a chain. Extending integration beyond the borders of a single company is especially important when involved in partnership. SCM comprises different inbound and outbound entities operating at various stages. Sourcing and sales are, by definition, boundary spanning functions. In supply 
chain management, the sourcing side has quite often been overlooked both by managers and researchers, and more attention has been paid to the outbound part.

Interdependence is of essence in DCM, because the key element in gaining competitive advantage from the adoption of the demand chain approach is the formation of mutual visions, goals, understanding and trust. It is also a prerequisite for partnership in the demand chains where entities see themselves as forming a unique, integrated body with a set of goals whose attainment will ultimately result in success and profitability for the entire supply chain.

Interdependence encompasses three aspects according to Kumar et al. (1995), namely the channel members' dependence, the degree of interdependence asymmetry between members of the network, and the network's global interdependence. Deep interdependence suggests wider-ranging, unity-type relationships between the parties and greater reliance on one another. Dependence and interdependence relations leading to power and influence of various types are main issues in understanding the behaviour in marketing channels (Ericsson 1976, Chapters 5-7).

The concept of interdependence is used as a discriminative criterion for supply chain configurations. Interdependence in the supply setting may be defined as the degree to which the success of a single entity depends on the decision of its counterparts in the supply chain (Stock and Boyer, 2009). They also describe four "crucial attributes" in the channel context, namely trust, decision-making, information sharing, and goal congruence.

The need for and degree of trust varies in different forms of supply chains. Different types of decision processes in the chains are also discussed, examples of which include myopic decision processes and dyadic decision processes. The issue of centralised versus decentralised decision making in different forms of chains is also analysed. The information flow is the nerve centre in any type of relationship, and it becomes especially crucial in partnership configurations. True goal congruence means that entities in the chain either feel that their objectives fully coincide with those of the supply chain, or, in the case of disparity, believe that their goals can be achieved as a direct result of working towards the objectives of the supply chain.

Lejeune and Yakova (2004) have developed a typology that can be used to describe various forms of supply chains. Their framework of "the $4 \mathrm{Cs}$ " is based on the interaction between the theory of relational forms (Fiske 1992) and the concept of interdependence (Thibaut and Kelly 1959). Lejeune and Yakova define four types of supply chain configurations, namely communicative, coordinated, collaborative, and co-opetitive configurations. The communicative configuration is characterised by shallow dependence and is related to Fiske's market pricing. This is the type of relationship we have referred to as "transactionoriented."

Mentzer et al. (2001) describe it as a supply chain that is "not managed" but "exists," and involves "as-needed" short term relationships for obtaining parity with competitors. Each entity acts on its own. A switch to other partners, which can provide more favorable purchasing terms and short term operational efficiency, is frequent in this context (Mentzer et al. 2001). This is the type of relationship that exists in "loose coalitions."

On the supply side, the distinction between vendors based on different types of relation- 
ships is well known. In Kraljic's (1983) purchasing matrix the suppliers in this group would be referred to as "non critical suppliers" delivering standardised, staple products with low impact on profitability and low risks in delivery. These suppliers can easily be replaced.

The coordinated configuration is characterised by deep dependence and is related to Fiske's authority ranking. The coordinated chain may be viewed as a hierarchy of entities in the supply chain, which is captained or dominated by a channel leader. It suits the cost-reduction objective. This configuration is well described in the evolution history of marketing channels. The captainship has shifted from raw materials supplier in the early days, to manufacturers, wholesalers to retailers. Today, the consumer is king. This is, in Kraljic's terminology, rather close to "leverage suppliers" with high impact on profitability, but low risk and complexity in the delivery aspect. These suppliers are rather easily replaced.

The collaborative configuration is characterised by shallow interdependence and is related to Fiske's equality matching. The chain entities are in a "symmetric relative dependence relationship" (Mentzer 2000). Often the set of common objectives is defined with respect to a particular function for which companies aim at "jointly developing solutions to common problems." An intimate relationship is created between entities for that focal function or activity, which very often is the inventory or transportation function. The alignment of the objectives is particularly strong for the focal function, while limited for the other functions. CPFR is an example of that kind of configuration. This configuration is akin to Kraljic's "bottleneck suppliers" with limited impact on profitability, but rather high risks in the delivery dimension. They are delivering specific competencies or products to the company and may, therefore, be quite hard to replace.

The co-opetitive configuration is characterised by deep interdependence and is related to Fiske's communal sharing. This is the type of suppliers that Kraljic would call "strategic suppliers" delivering products with high impact on profitability, complexity and risk in the chain. They have a major influence on the company's profitability and performance and are very hard to replace.

The set of common objectives will have an extended scope for the co-opetitive chain, because they are concerned with more than one single function or process. The co-opetitive configuration is the one we relate to the demand chain concept.

The concept of co-opetition was introduced by Brandenburg and Nalebuff (1996) as a combination of cooperation and competition. It rests on the assertion that even competitors on the horizontal level can benefit when they work together, if that is legal. In the vertical dimension, it suggests that the degree of coordination and alignment increases, while the degree of conflict is reduced. Co-opetition is seen as a "plus-sum" game, in which the sum of what is gained by all parties is greater than the sum of what the parties entered the game with.

Co-opetition is also associated with the concept of complementors, that is, entities that add value to the other entities' products and make them more attractive to the customers. Competitors, on the other hand, can be defined as entities that make each other's products less valuable in the eyes of the buyer. 
Ericsson (1976) distinguishes between three types of competitors, here referred to as Groups I, II and III. Group I consists of all companies marketing products satisfying the same need and which are made of the same main raw materials. Group II consists of all companies marketing products that can be used to satisfy the same need, but which are not of the same origin. Finally, Group III consists of all companies that are interdependent because their customers have to allocate their scarce resources to products satisfying very different needs (p. 106).

Complementors, on the other hand, are entities involved in different stages of the marketing channel (suppliers and manufacturers, for example). Ericsson (1976) distinguishes between the interplay in Horizontal Competition Systems (HMS) and VMS. It is also a distinction made between "channels" for Group I flows, "channel groups" for Group II flows and "channel networks" for Group III flows. In this way, the economic system (the network) is defined as HMSs on different levels and VMSs (flows) cutting across the levels.

Competitors are supposed to act on the same stage in the network (two retailers, for example) and they can join in lateral collaboration, for example in joint transportation to reduce cost and pollution in urban areas. Lateral transshipment of inventory, i.e. movements of inventory between entities in the horizontal market system, may increase leagility, but are quite hard to get to work in practice.

Transshipment policies applied to expensive low-demand items can result in decrease of up to $20 \%$ of the inventory and transportation costs (Greis and Kasarda 1997). The airline industry has this kind of cooperation regarding very expensive components such as aircraft engines. The car industry made an attempt to this end with their Covisint approach. To implement mechanisms such as lateral transshipments, the information flow needs to be nurtured by all entities in the cooptive network. Greis and Kasarda (1997) define this as a "web of exchange" that ties together all collaborating entities in the network.

The demand chain concept focuses on complementors and their roles in the partnership for creating unique competence. In the demand chain there is a set of commonly agreed upon goals that are pursued by the partners. In the collaborative chain, the objectives are usually defined with respect to a focal function, but in the co-opetitive chain (the demand chain) they have an extended scope to other functions and the four core processes.

In Lejeune and Yakova's discussion of co-opetitive demand/supply chains, it is stated that such chains may help secure not only specific inputs like products, but also "the technical expertise surrounding them" that can provide different types of service to increase the value added to the customers.

By using complementary external assets, companies may be involved in common research and development projects, leading to technological development and acquisition (Hamel et al. 1989). Such technological development and the new digital infrastructure is a major enabler of this type of boundary spanning product and process development. Cooperation and alignment with customers as well as suppliers in this respect is increasing rapidly thanks to new tools such as service oriented architectures (see, for example, Mulholland et al. 2006). This cooperation leads to mutual improvement and external economies, but it also exposes the partners to significant risks, which may only partially be prevented by contracts. The contracts, however, cannot consider all contingencies. It is impossible 
to anticipate each partner's contribution, and the resulting profit allocation. This has been highlighted several times when innovators and entrepreneurs come in conflict with investors of risk capital. Therefore, goodwill trust is needed. Trust is one of the key concepts in demand chains and the partnership is based not only on a reliability and competency trust, but also on a good will trust, which can be seen as a higher level of mutual confidence.

The common development requires what Lejeune and Yakova call "true goal congruence" among partners. This is associated with the goodwill trust between the partners and the belief of the benevolence of each of them.

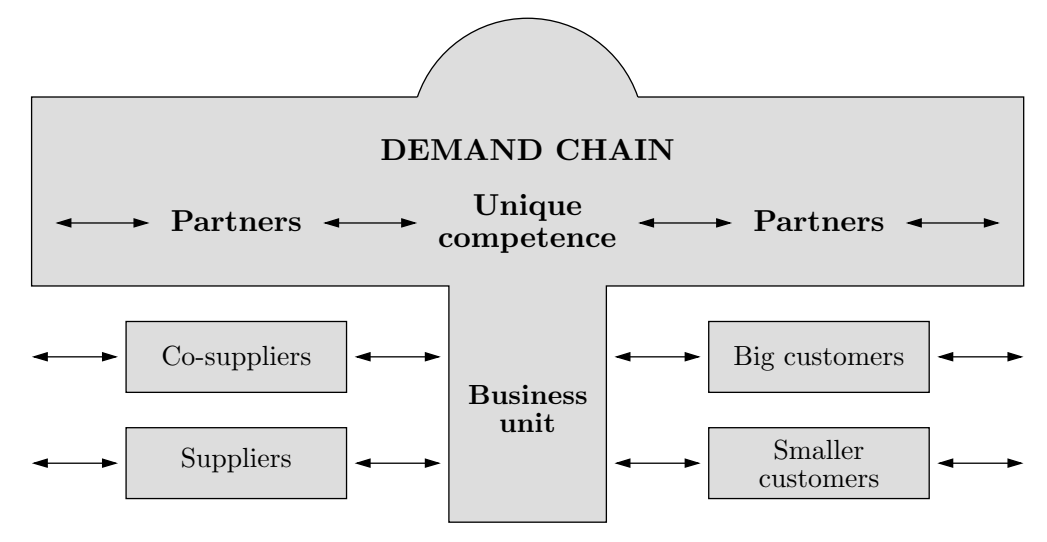

Figure 11: Different relationships in a network of supply chains, ranging from loose coalitions to interdependent partnerships, i.e. demand chains.

The concept of a portfolio of supply chains ranging from loose coalitions (communicative configurations) to demand chains (co-opetitive configurations) as illustrated in Figure 11. On the third level, we have the type of ad hoc, transaction oriented connections between independent organisations that conducted business amongst one another. This is the type of environment in which the first generations of logistics were evolved. In Lejeune and Yakova's terminology it is a communicative configuration. On the second level, more stable relations of SCM type are emerging, and different forms of cooperation and integration are established. This is similar to coordinated and collaborative configurations. Finally, on the first level the type of close, interdependent partnership which leads to demand chains, as defined here, are emerging. This is what Lejeune and Yakova call co-opetitive configurations.

\section{Conclusion}

SCM has been discussed and some weaknesses have been identified. Gattorna (2010, p. $\mathrm{XI})$ also discusses the term and states that

"Supply Chain Management never was a good term because it immediately conjured up in one's mind the 'supply' side of the enterprise. The 'chain' descriptor doesn't help either, as it implies we are dealing with linear chains 
or strings of enterprises, when in fact the real world involves three-dimensional arrays of enterprises. Indeed, our future world, whether we like it or not, is moving inexorably towards a 'network of networks', and we had better get onboard with the reality.

Although it is probably a little early to move straight to the term value network, I forecast that it will become widely adopted within ten years.

By ultimately embracing 'value networks' as the accepted vernacular in the future we automatically include all parties on the supply-side, all parties on the demand-side, and all parties in between, for example service-providers."

Ericsson (2003) describes eNets as value networks enabled by concurrent digital infrastructure and argues that

“... the concept of supply/demand or value chain is a simplification of reality. A company is not part of just one single chain, but it is simultaneously part of a huge network of chains and relationships. In some relations the focal company serves as a supplier, in others as a customer, an intermediary or a complementor. Important roles are played by intermediaries (such as third party logistics companies) or complementors (such as electronic market places). These add products and services that expand the reach and range of a network's total offering. Many-to-many relationships make it important to clarify the role of each of the players in a value network. However, the roles are not fixed, and co-operation and competition may exist at the same time. Co-opetition becomes an increasingly important concept in evolving value networks."

The primary building blocks of the supply/demand network are the focal company and its direct 'exchange partners.' Their shared focus on creating customer value is necessary to determine and define the proper relationships between the partners in the network.

The process and systems integration induced by supply/demand chain management leads to increasingly complex networks of relations between a company and its environment. This development is further hastened by the increased use of outsourcing and also by developments within e-commerce and e-business. There is a move towards more and more complex networks, e-nets, with supply/demand chains and value nets serving as important links. Continuous improvement and rethinking combined with rapid inflow of new technology make it possible to move channel cooperation one step further and benefit from e-nets, forming the next major phase of Internet applications.

The concept of collaboration in e-nets is fundamental for understanding the shift from value chains to value networks and the accompanying move from supply/demand chains to supply/demand networks. Relationships in complex supply/demand networks are very hard to describe and conceptualise. Metaphors are enlightening in these situations. Johansen and Swigart (1994) used the metaphor of a fishnet to describe the intraorganisational evolution from company hierarchies to network organisations. They concluded that electronic networks are replacing office buildings as the locus of business transactions, and stated that, 'your network is your business.' This is also true for the new network structures emerging between supply/demand chains. 
The e-net is similar to a fishnet where every node has a relation to every other, either directly or indirectly. When a node in the fishnet is lifted by the network captain the rest of the net lattices nicely under it. A temporary hierarchy, a value net, designed to fulfil a certain need, evolves. Layers will appear consistent with how high the node is lifted and the width of the mesh. The fishnet can form and reform various patterns of connection. The consumer, the competitor, the supplier etc. may at one time be in the apex, at another in the middle. This means that different e-nets can be defined depending on the focus, which might be consumers, competitors, suppliers, etc.

The fishnet rearranges itself quickly and complex, yet flexible, webs of interconnection appear. ICT, including a combination of telecom and computing, are the cords of which the interorganisational fishnet between companies is woven (Ericsson 1996). Development of fishnet structures may be expensive, but the innovation will lead to new business opportunities. Value innovation is one example of this. ICT can help cable up the fishnet structure to make things happen that were not possible before. This requires a special brand of vision to trigger the use of new technology. Technology is the tool of change, but not the main cause.

The statement that the proof of the pudding is in the eating, is valid for testing the usefulness of theoretical concepts as well. The question is whether there is any practical proof that business is working along the DCM lines, even if they do not use the term. It was within Fast Moving Consumer Goods (FMCG) that we first saw signs of the development toward increased collaboration and integration. A number of methods and techniques evolved as a result of changes in competition, examples of which are Quick Response (QR), Efficient Consumer Response (ECR), CPFR, and Vendor Managed Inventory (VMI).

Companies like Walmart, IKEA, Benetton, Zara, H\&M, BAMA and others are examples of companies that were not fighting volatility but rather taking advantage of it. The ball bearing company SKF is perhaps the best example of continuous rethinking and logistics innovation in traditional industry. SKF has always been a spearhead and pioneer in terms of development and implementation of state of the art logistics. Electrolux' concept of Demand Flow Leadership is another example of process oriented, consumer focused approaches. Companies may not always use the term DCM, but the approaches are similar. One of the most important characteristics of the new approach is a shift of focus from the technical infrastructure and cost efficiency to people as the driving force in development and implementation.

The DCM concept as it is used here, is one step towards a "Value Network" approach. Different sets of relationships make up the links in the network. The nodes consist of all sorts of organisations and individual consumers. In an increasingly turbulent environment, resilience is becoming a more important concept in building relationships. The term supply chain envisions a sequence of activities, functions and organisations. Even in organisations, decisions are made by individuals with their specific strengths and weaknesses. The key ingredients in modern supply chains are not the vehicles, the equipment or the digital infrastructure. The most important ingredient is the people who design, develop and run them. Only people can drive and implement changes. It becomes increasingly evident that supply chains are living organisations driven by people power. This is one of the main characteristics of the demand chain approach and it will be further accentuated in 
the future.

Some common characteristics may be identified in successful change processes:

1. The transformation is led by a "soul of fire," an entrepreneur and pioneer who takes charge and infuses the company with his values. These change leaders have the ability to create enthusiasm and positive energy among the employees. They are pioneers who walk in front of the troops, but not so far ahead that people loose sight of them. They also know how to avoid being caught in the definition of pioneers as "the one that walks first, with an arrow in his back."

2. Real change leaders also have a holistic view of the entire flow and an ability to convince partners that synchronisation and alignment is a win-win concept.

3. Consumers or end users are focused and taken as the starting point for development of differentiated and customised chains. Consumer insight, deep and thorough knowledge of the consumers' implicit and explicit needs and wishes, is the basis and core of the approach.

4. The approach is based on "state of the art" technologies and techniques when this is appropriate, but the trick is to know when they do not fit. Management by Fad, jumping on the latest hype, without understanding the underlying theory and circumstances, is a certain road to chaos.

5. They are people powered in the true sense of the word.

To affect lasting change, it is not enough to have the availability of new tools and techniques, and it is not sufficient to proclaim a new glorious strategy. The key to success is people. An icon, a change leader, who really can take charge, is needed. The examples from business are numerous. Thomas Watson at IBM, Ray Kroc at McDonalds, Jack Welch at General Electric, Sam Walton at Walmart, Bill Hewlett and Dave Packard at HP, Michael Dell at Dell, Steve Jobs at Apple and Ingvar Kamprad at IKEA are just a few examples of the type of entrepreneurs that have succeeded. One of the common characteristics of these leaders is the ability to create enthusiasm and a willingness to follow among fellow employees.

It is also important to have rethinking and entrepreneurship flourish on all levels in the organisation. Innovation is not only for top management, but also for "demand flow champions" that are given the opportunity to emerge around the organisation.

The answer to the question initially asked "Do we really need new concepts or will they just add to the confusion?" can be answered in the affirmative. And there are signs of implementation of the DCM concept.

\section{References}

[1] Ammer DS, 1980, Materials management and purchasing, $4^{\text {th }}$ Edition, RD Irwin, Homewood (IL).

[2] Bucklin LP, 1966, A theory of distribution channel structure, Institute of Business and Economic Research Special Publications, Berkeley (CA).

[3] Christopher M, 1992, Logistics and supply chain management, Pitman Publishing, London.

[4] Cooper MC, Lambert DM \& PAGH JD, 1997a, Supply chain management: More than a new name for logistics, The International Journal of Logistics Management, 8(1), pp 1-14. 
[5] Cooper MC, Ellram LM, Gardner JT \& Hanks AM, 1997b, Meshing multiple alliances, Journal of Business Logistics, 18(1), pp 67-89.

[6] Council of Logistics Management, 1992, What's it all about?, Oak Brook, Chicago (IL).

[7] Croxton KL, Garcia-Dastuque SJ \& Lambert DM, 2001, The supply chain management processes, The International Journal of Logistics Management, 12(2), pp 13-36.

[8] Council of Supply Chain Management Professionals, 2011, Definition of supply chain management, [Cited June 7th , 2011], [Online], Available from http://www.cscmp.org.

[9] Davenport TH, 1993, Process innovation: Reengineering work through information technology, Harvard Business School Press, Boston (MA).

[10] De Treville S, Shapiro RD \& Hameri AP, 2004, From supply chain to demand chain: The role of lead time reduction in improving demand chain performance, Journal of Operations Management, 21(6), pp 613-627.

[11] Ellram LM \& COOPER MC, 1990, Supply chain management, partnership and the shipper-thirdparty relationship, The International Journal of Logistics Management, 1(2), pp 1-10.

[12] Ericsson D, 1965, The choice of marketing mix in industry, HHG, School of Business, Gothenburg.

[13] ERICsson D, 1969, Materials administration/logistik, Hermods, Malmö.

[14] ERICSSON D, 1974, Materials administration, McGraw-Hill, New York (NY).

[15] ERICsson D, 1976, Vertical marketing systems: Design and development, PhD Dissertation, University of Gothenburg, Gothenburg.

[16] Ericsson D, 1981, Materials administration/Logistics - An executive perspective, Liber Press, Malmo.

[17] Ericsson D, 1996, Virtual integration, Unisource, Norcross (GA).

[18] ERICSSON D, 2000, eLogistics: Key to success in the digital economy, Proceedings of the Eurolog 2000 - Logistics Challenges - Better, Faster, Cheaper, Athens, Greece.

[19] ERICSSOn D, 2003, Supply/Demand chain management: The next frontier for competitiveness, pp. 117-135 in Walters D (ED), Global logistics and distribution planning, Kogan Page, London.

[20] Ericsson D, 2007, Demand flow leadership and the evolution of management concepts, pp. 129-146 in Walters, D (ED), Global logistics: New directions in supply chain management, Kogan Page, London.

[21] Fisher ML, 1997, What is the right supply chain for your product?, Harvard Business Review, 75(2), pp. $105-116$.

[22] FIske AP, 1992, The four elementary forms of sociality: Framework for a unified theory of social relations, Psychological Review, 99(4), pp. 689-723.

[23] Forrester JW, 1969, Principles of systems, Wright-Allen Press, Cambridge (MA).

[24] Gattorna J, 1998, Strategic supply chain alignment, Gower Publishing, London.

[25] Gattorna J, 2010. Dynamic supply chains, Prentice Hall, London.

[26] GREen M, 1989, The evolution of the Swedish concept of materials administration from a conceptual perspective to an established discipline, CTH, Chalmers University of Technology, Gothenburg.

[27] Greis NP \& Kasarda JD, 1997, Enterprise logistics in the information era, California Management Review, 39(4), pp. 55-78.

[28] Hamel G, Doz YL \& Prahalad CK, 1989, Collaborate with your competitors - And win, Harvard Business Review, 67(1), pp. 190-196.

[29] Hammer M, 2001, The superefficient company, Harvard Business Review, 79(9), pp. 82-91.

[30] HeIKKILÄ J, 2002, From supply to demand chain management: Efficiency and customer satisfaction, Journal of Operations Management, 20, pp. 747-767.

[31] Heskett JL, Glaskowsky NA \& Ivie RM, 1964, Business logistics, The Ronald Press Company, New York (NY). 
[32] Hewitt F, 1994, Supply chain redesign, The International Journal of Logistics Management, 5(2), pp. $1-10$.

[33] HJorT K, 2010, Returns avoidance and gatekeeping to enhance e-commerce performance, CTH, Chalmers University of Technology, Gothenburg.

[34] Johansen R \& Swigart R, 1994, Upsizing the individual in the downsized organization, AddisonWesley, Harlow.

[35] Keen PGW, 1988, Competing in time, Ballinger Publishing Company, Cambridge (MA).

[36] Kim WC \& Mauborgne R, 2005, Blue ocean strategy - How to create uncontested market space and make the competition irrelevant, Harvard Business Press, Cambridge (MA).

[37] Kraljic P, 1983, Purchasing must become Supply Management, Harvard Business Review, 25(6), pp. 109-117.

[38] Kumar N, Scheer LK \& Steenkamp JB, 1995, The effects of perceived interdependence on dealer attitudes, Journal of Marketing Research 32, pp. 348-356.

[39] LAmBERT DM, 1994, The international center for competitive excellence, University of North Florida, Jacksonville (FL).

[40] LAmbert DM \& COPER M, 2000, Issues in supply chain management, Industrial Marketing Management, 29(1), pp. 65-83.

[41] La Londe BJ, 1984, A reconfiguration of logistics systems in the 80s: Strategies and challenges, Journal of Business Logistics, 4(1), pp. 1-11.

[42] Lejeune MA \& Yakova M, 2005, On characterizing the 4 Cs in supply chain management, Journal of Operations Management, 23(1), pp. 81-100.

[43] Mentzer JT, De Witt W, Keebler JS, Min S, Nix NW, Smith CD \& Zacharia ZG, 2001, Defining supply chain management, Journal of Business Logistics, 22(2), pp. 1-25.

[44] Mulholland A, Thomas CS, Kurchina P \& Woods D, 2006, Mashup corporations: The end of business as usual, Evolved Technologist Press, New York (NY).

[45] Oliver RK \& WeBber MD, 1982, Supply-chain management: Logistics catches up with strategy, Outlook in Christopher M (ED), Logistics — The strategic issue, Chapman and Hall, London.

[46] O'Marah K \& Hofman D, 2010, The AMR Supply Chain Top 25 for 2010, Technical Report ID G00201212, Gartner Inc., Stamford (CT).

[47] Ruppenthal KM \& McKinnell HA, 1968, Business logistics in American industry, Graduate School of Business, Stanford University, Stanford (CA).

[48] Selen W \& Soliman F, 2002, Operations in today's demand chain management framework, Journal of Operations Management, 20(6), pp. 667-673.

[49] Shaw A, 1912, Some problems in market distribution, Harvard University Press, Cambridge (MA).

[50] Stevens GC, 1989, Integration of the supply chain, International Journal of Physical Distribution and Logistics Management, 19(8), pp. 3-8.

[51] Sтоск JR, 2009, A research view of supply chain management: Developments and topics for exploration, ORiON, 25(2), pp. 147-160.

[52] Stock JR \& Boyer S, 2009, Developing a consensus definition of supply chain management: A qualitative study, International Journal of Physical Distribution and Logistics Management, 39(8), pp. 690-711.

[53] Thibaut JW \& Kelley HH, 1959, The social psychology of groups, Wiley, New York (NY).

[54] Van Crefeld M, 1977, Supplying war, Cambridge University Press, Cambridge (MA).

[55] Von Clausewitz C, 1967, On war, Penguin Books, London. 
